\title{
Osmotic Stress Effect over Carbohydrate Production in a Native Starin of Scenedesmus sp.
}

\author{
Pilar Bremauntz $^{1 *}$, Luis C. Fernández-Linares ${ }^{1}$, Rosa O. Cañizares-Villanueva ${ }^{2}$ \\ ${ }^{1}$ Laboratory of Bioprocesses, Department of Bioprocesses, Unidad Profesional Interdisciplinaria de Biotecnología (UPIBI), Instituto \\ Politécnico Nacional, México, D.F., México; ${ }^{2}$ Departamento de Biotecnología y Bioingeniería, Centro de Investigación y de Estudios \\ Avanzados, Instituto Politécnico Nacional, México, D.F., México. \\ Email: *pilarbrem@yahoo.com.mx
}

Received November $11^{\text {th }}, 2013$; revised December $9^{\text {th }}, 2013$; accepted December $30^{\text {th }}, 2013$

Copyright (C) 2014 Pilar Bremauntz et al. This is an open access article distributed under the Creative Commons Attribution License, which permits unrestricted use, distribution, and reproduction in any medium, provided the original work is properly cited. In accordance of the Creative Commons Attribution License all Copyrights @ 2014 are reserved for SCIRP and the owner of the intellectual property Pilar Bremauntz et al. All Copyright (C) 2014 are guarded by law and by SCIRP as a guardian.

\section{ABSTRACT}

The production of biofuels is currently presented as a possible answer in the search for sustainable alternatives for the total or partial substitution of fossil fuels. One of the most successful biofuels that have been developed is bioethanol. However, bioethanol production has been limited since it relies on the use of sugar cane or cereals. These materials are important sources of food and their demand as both a biofuel and a foodstuff has led to the price increase and may lead to possible shortages. Our group has focused on searching for native microalgae as sources of carbohydrates and bioethanol, with the goal of finding a sustainable source of bioethanol. Currently, twelve different strains which reach growth rates between $0.7-1.8 \mathrm{~g} / \mathrm{L}$ and present carbohydrate production under osmotic shock conditions have been isolated. In this work, we demonstrate the results obtained with the Chlorella sp. [1] strain and the results obtained with the Scenedesmus sp. strain. The Scenedesmus sp. strain showed an increase in the production from 22 to $650 \mathrm{mg} / \mathrm{sugar} / \mathrm{g}$ of biomass (dry weight), after 24 hours of osmotic shock with $0.1 \mathrm{M} \mathrm{NaCl}$. The osmolytes which were produced after osmotic shock were identified as sucrose and trehalose, both of which are fermentable. These results demonstrate that this strain, through the photosynthetic pathway and osmotic shock, is a potential source of fermentable sugars.

\section{KEYWORDS}

\section{Biofuels; Bioethanol; Microalgae; Scenedesmus sp.; Carbohydrates}

\section{Introduction}

Microalgae are oxygenic photosynthetic organisms that are found in diverse environments such as salt water and fresh water. They are even found in environments as extreme as desserts. The majority of these organisms are photosynthetic species, as such they are capable of producing sugars from $\mathrm{CO}_{2}$ and light [2-4]. Sugar production in these algae has been shown to increase as a response to osmotic shock generated by high salt concentrations, a mechanism known as osmoregulation [5,6].

Much is known about the large quantity of compounds that the algae produces as osmoregulators. These compounds range from simple carbohydrates to amino acids

${ }^{*}$ Corresponding author. and even complex compounds such as digenosides $[7,8]$.

Some of these osmoregulators synthesized by algae can have commercial uses. This is the case for glucose, sucrose, and trehalose which can even be fermented to produce bioethanol [1].

The production of bioethanol is a technology that has been established in countries like Brazil and the United States [9], and usually is obtained from either the fermentation of starch from different materials such as wheat or direct fermentation of carbohydrates using sugar cane or even from lignocellulose residues [10]. However, the production of bioethanol from primary sources that are food is not sustainable due to inevitable competition with human consumption. Hence, the production of bioethanol from microalgae biomass could be an attract- 
tive alternative. One possible way to take advantage of this alternative is to increase the amount of fermentable carbohydrates in the biomass [11]. The object of this work was to calculate the production of fermentable carbohydrates during osmotic shock with $\mathrm{NaCl}$ by an isolated strain of Scendesmus.

\section{Materials and Methods}

\subsection{Isolation and Cultivation}

Twelve sites of four aquifers were sampled: Texcoco Lake, Guadalupe Lake, Lake Tabasco, Tames River, Canada. The $\mathrm{pH}$ and salinity of each sample was determined.

The samples were enriched with four culture media, according to the salinity of the site of their acquisition, BG11, BG11/saline (25 g/L) and Guillar F/2 media [12], in the culture conditions reported [1]. After replanting two times in liquid media, the algae that demonstrated the largest growth were planted in the solid culture media with $10 \%$ agar-agar. Upon isolation the colonies were replanted in liquid media.

\subsection{Growth Kinetics}

$250 \mathrm{~mL}$ beakers with an operational volume of $150 \mathrm{~mL}$ were inoculated with $10 \%$ of a preculture of each isolated microalgae. Each culture was grown for ten days in the same conditions. Growth was monitored through absorbance (at $600 \mathrm{~nm}$ ) in a Genesis colorimeter $10 \mathrm{UV}$ and by dry weight every $24 \mathrm{~h}$.

\subsection{Analysis of Intra- and Extracellular Sugars}

The determination of extracellular sugars was done through the separation of the supernatant followed by the Dubois method [13].

To determine intracellular sugars, a modified Muller method was used for the extraction [1], followed by quantification through the Dubois method.

The sugars were identified through HPLC, through a method described by Bremauntz et al. [1].

\subsection{Effects of Stress on Growth and the Effect of Osmotic Shock on the Production of Sugars}

To test the effects of $\mathrm{NaCl}$ on growth, the strains were cultivated in BG11 with 0.2, 0.4 and $0.6 \mathrm{M} \mathrm{NaCl}$ under the previously described conditions. The intra and extracellular sugar concentrations were determined during the analysis of the growth kinetics.

The osmotic shock showed effects as previously described in Bremauntz et al. [1].

\section{Results and Discussion}

\subsection{Isolation and Growth}

The isolation of twelve strains, which were characterized by optical microscopy, was accomplished. Of the twelve strains, three were identified as cyanobacteria and nine were identified as eukaryotic microalgae. Seven of the strain showed growth greater than $1 \mathrm{~g} / \mathrm{L}$ (Table 1).

Growth kinetics showed Cystcoccus sp, Synechocystis sp, Scenedesmus sp, and Clorella sp. had the largest amount of growth (Figure 1). All of these strains showed their maximum growth between days nine and elven. Specifically, Scenedesmus sp. presented a maximum growth of $1.58 \mathrm{~g} / \mathrm{L}$ with a $\mu_{\max }$ of 0.0059 [14]; however, other authors reached values up to $1.069\left(\mathrm{~h}^{-1}\right)$, and growth of $2.63 \mathrm{~g} / \mathrm{L}[15,16]$. From this we are able to determine that the BG11 culture media and that cultivation conditions were appropriate for the growth of Scenedesmus sp.

\subsection{Production of Sugars}

For the production of sugars the efficiency of production of each isolated strains was determined (mg of sugar produced per liter of culture). These determined values established that the strains with the greatest efficiency were: Chlorella, Chrysosphaera, Trebouxi, and Scenedesmus, with values of 29.11, 6.22, 5.44, and $5.37 \mathrm{mg} / \mathrm{L}$, respectively (Figure 2).

For the four strains the intra- and extracellular sugars

Table 1. Identification of algae that presented the most growth and their biomass production.

\begin{tabular}{cccc}
\hline Order y Genus & Origen & Maximun Biomass $(\mathrm{g} / \mathrm{L})$ & $\mu_{\max }\left(\mathrm{h}^{-1}\right)^{*}$ \\
Oscillattoriales Lyngbya & Texcoco Lake & 2.56 & 0.928 \\
Chroococcales Cystococcus & Texcoco Lake & 1.76 & 0.126 \\
Chroococcales Synechocystis & Texcoco Lake & 1.74 & 0.301 \\
Chlorococcales Scenedesmus & Tamesi River Canada & 1.58 & 0.479 \\
Chlorococcales Chlorella & Guadalupe Lake & 1.36 & 0.628 \\
Oscillattoriales Oscillatoria & Tamesi River Canada & 1.24 & 0.313 \\
Chroococcales Synechocystis $(T)$ & Camarón Lake, Tabasco & 1.18 & 0.413 \\
\hline
\end{tabular}

${ }^{*} \mu_{\text {max }}$ at $25^{\circ} \mathrm{C}$, medium BG11, aereation $4 \mathrm{vvm}$ e light intensity $100 \mu$ moles de fotons $/ \mathrm{m}^{2} \mathrm{~s}$. 


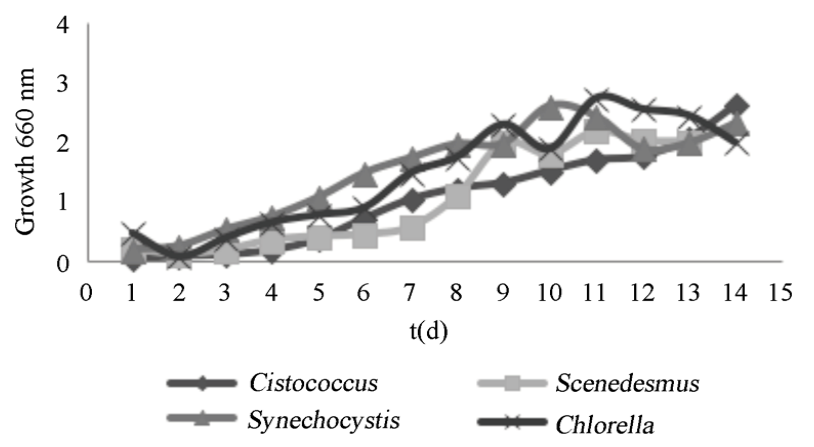

Figure 1. Growth of isolated strains in BG11 medium at $25^{\circ} \mathrm{C}, 4 \mathrm{vvm}, \mathrm{y} 100 \mu \mathrm{mols}$ fotons $/ \mathrm{m}^{2} \mathrm{~s}$.
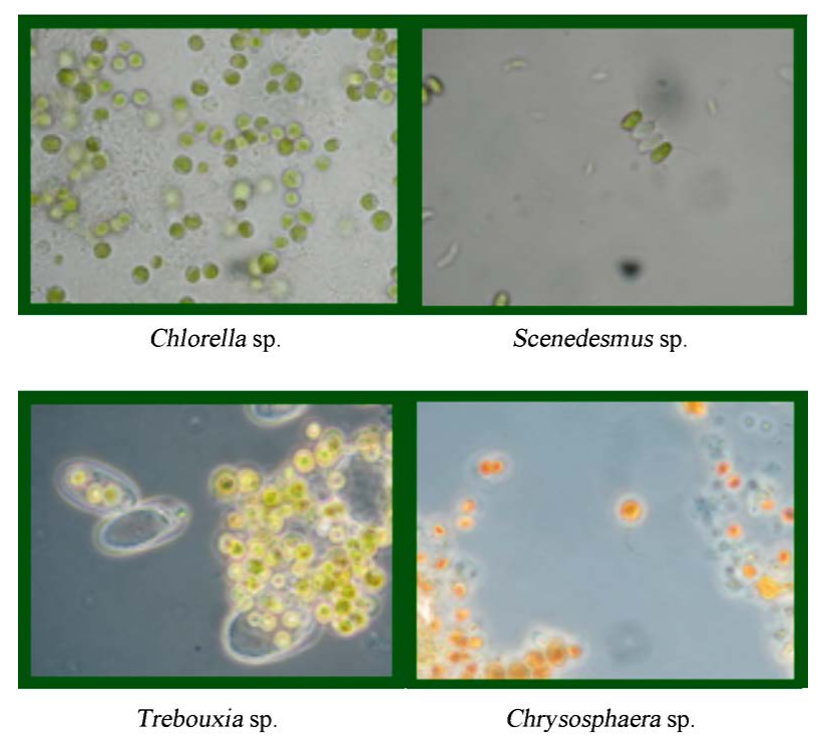

Figure 2. Optical Microscope images $(100 \times)$ of the four strains with the greatest sugar production efficiency.

concentrations were determined. For Scenedesmus sp. only intracellular sugars, were found. The intracellular sugars a concentration of $5.48 \mathrm{mg} / \mathrm{L}$, a sugar content of $38 \% \mathrm{~g} / \mathrm{g}$ which is a value greater that that reported by Miranda et al. [11]. Miranda et al. reported that in studies of geometric and design optimization of bioreactors for Scenedesmus sp. reached a production of sugars of 29\%; however, results reported by Shih-Hsin et al. [15] reached carbohydrate production of $46.65 \%$ with nitrogen limitations in the media. It has been observed in the literature that the formulation of the culture media as well as the quantity and intensity of the light used and even the design of the bioreactor can influence the production of sugars, lipid, proteins, and even the morphology of the genus Scenedesmus [17].

\subsection{Effect of the $\mathrm{NaCl}$ Concentration on Growth}

In all three $\mathrm{NaCl}$ concentrations used the growth of Scenedesmus sp. was inhibited (Figure 3 ). In other studies, Scenedesmus incrassatulus Bohl, growth was decreased

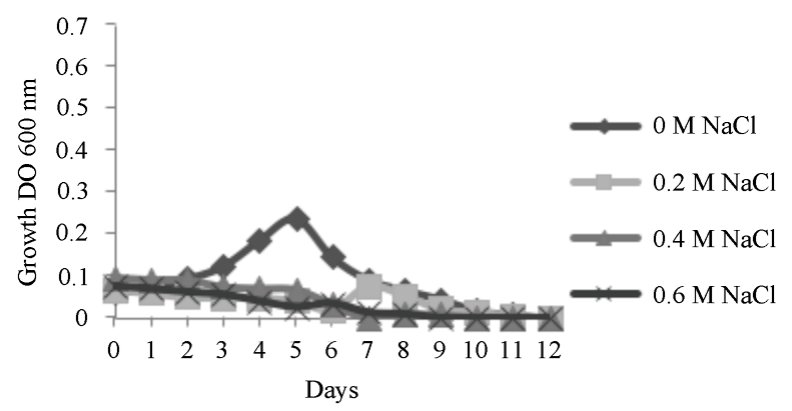

Figure 3. Effects of $\mathrm{NaCl}$ concentration on the growth of Scenedesmus sp.

with a $\mathrm{NaCl}$ concentration of $0.175 \mathrm{M}$ [18], showing a reduction in the fixation of carbon dioxide and an increase in the production of proline. On the other hand, Demetriou et al. [19], reported inhibited growth, by measuring the production of pigments in Scenedesmus when the concentration of $\mathrm{NaCl}$ in the media was greater that $0.2 \mathrm{M}$; however, the production of sugars and proteins was increased when the concentration of salt was increased to $0.4 \mathrm{M}$ [20]. Sheng Shu and his group completed studies with salt near metabolic levels with $\mathrm{NaCl}$ concentrations of $0.075 \mathrm{M}$, demonstrating that it affects photosynthetic metabolism. They found that osmotic stress inhibits the maximum production of photochemical PSII $\left(F_{v} / F_{m}\right)$, through the competition of the receptor site of PSII. Through the addition of saline solution the destruction of thylakoids in the chloroplasts was observed [21]. This was observed through the growth experiments where after $24 \mathrm{~h}$ after inoculation in salt media, coloration was lost and the media went from green to white. Authors such as El-Sayed have reported a decrease of $50 \%$ of the chlorophyll content after immersion of a strain of Scenedesmus sp. in $1.5 \mathrm{M} \mathrm{NaCl}$ [22].

\subsection{Effects of Osmotic Shock on Sugar Production}

When the Scenedesmus sp. strain underwent osmotic shock an increase in the extracellular sugar production rate from $24 \mathrm{~h}$ after the shock 22 to $650 \mathrm{mg} / \mathrm{g}$ p.s. as observed $24 \mathrm{~h}$ after the shock (Figure 4). The osmotic solution had a concentration of $0.1 \mathrm{M}$. However, after $48 \mathrm{~h}$ or exposure, the increase in sugar production slows notably, where the production reaches a rate of $235 \mathrm{mg} / \mathrm{g}$ p.s. This represents a 10 times increase in the rate of production of sugars when compared to the production rate without an osmotic shock treatment and after $72 \mathrm{~h}$ of treatment. This matches results from experiments on the effects of salinity on the growth of this strain, where it was shown that $\mathrm{NaCl}$ inhibited growth after $72 \mathrm{~h}$ (Figure 3).

These results differ from those obtained by other authors for other species of Scenedesmus [22,23]. Kirrolia reported an increase in total carbohydrates from 0.04884 


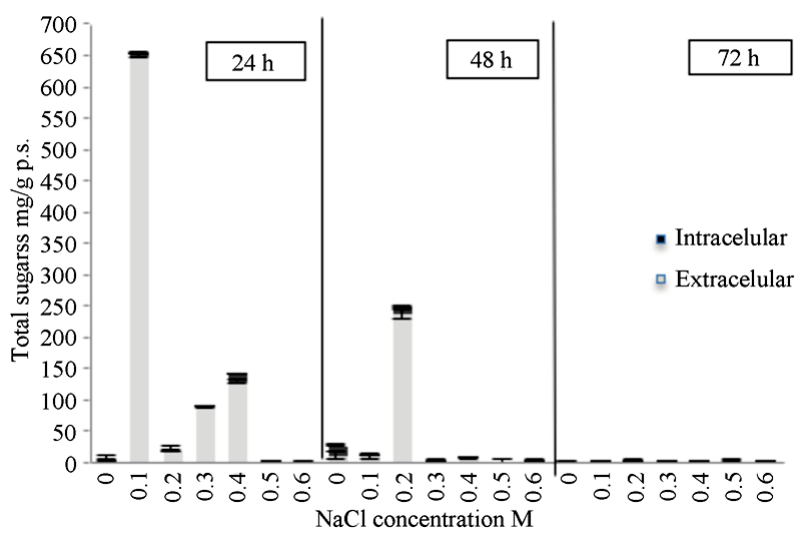

Figure 4. The effect of osmotic shock on the production of total sugars in Scenedesmus sp. in media BG11. Intracellular sugars and extracellular sugars.

to $0.06237 \mathrm{mg} / \mathrm{ml}$ in an isolated strain of Scenedesmus quadricauda in an osmotic shock solution of $0.2 \mathrm{M} \mathrm{NaCl}$ during the course of 10 days.

Analysis of both intracellular and extracellular carbohydrates (Figures 5 and 6) showed that the concentration of sucrose and trehalose increased notably in the extracellular fraction. There was $76 \%$ increase in sucrose concentration and a 37\% increase in trehalose concentration. In the intracellular fraction, sucrose concentration increased $92 \%$ and there was no increase in trehalose concentration.

These results indicate that the principal osmoregulator produced by this strain of Scenedesmus sp. is sucrose and trehalose, while to a lesser extent than sucrose, also functions as an osmoregulator. The discovery of trehalose as an osmoregulator in Scenedesmus sp. has not been reported by any other group. Other groups have reported increases in the production of sucrose and trehalose in the initial phase of osmotic shock followed by stabilization after $48 \mathrm{~h}$ of the shock for generic Scytonema [24]. They also mentioned that the production of trehalose contributes to the stabilization of proteins in the cell membrane.

\section{Conclusions}

This work demonstrates that osmotic shock of Scendesmus sp. with a concentration of $0.1 \mathrm{M}$ can increase the production of carbohydrates $24 \mathrm{~h}$ after the shock. The carbohydrates produced are sucrose $(0.464 \mathrm{mg} / \mathrm{g}$ p.s.) and trehalose $(0.112 \mathrm{mg} / \mathrm{g}$ p.s.). These carbohydrates were obtained in amounts larger than previously reported, or in the case of trehalose, not having been previously reported.

These simple sugars were highly attractive as possible as prime material for the production of bioethanol through simple fermentation. Direct fermentation of these sugars has been shown to be more efficient than

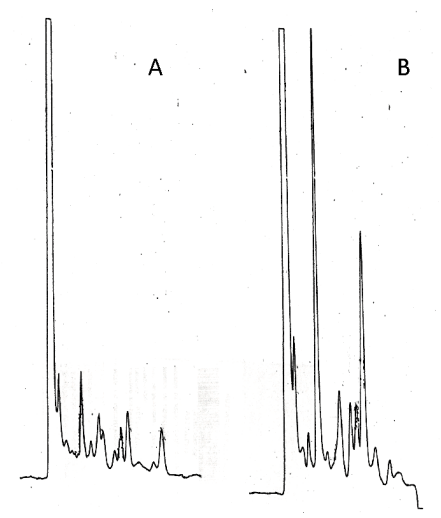

Figure 5. HPLC chromatograms of extracellular extract in Scenedesmus sp. without osmotic shock treatment (A) and with osmotic shock treatment of $0.1 \mathrm{M}$ after $24 \mathrm{~h}$ (B).

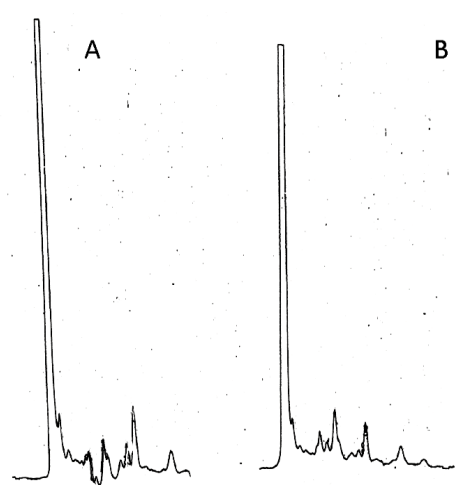

Figure 6. HPLC chromatograms of intracellular extract in Scenedesmus sp. without osmotic shock treatment (A) and with osmotic shock treatment of $0.1 \mathrm{M}$ after $24 \mathrm{~h}$ (B).

strategies proposed by other groups who have tried producing bioethanol through an increase in cellulose/starch in the membrane of various microalgae, including Scendesmus [17,25-27].

\section{Acknowledgements}

Funding by Instituto Politecnico Nacional PIFI-20100242.

The microscopy studies and strain identificactions were led by Dr. Ma. Esther Meave from Univesidad Autónoma Metropolitana, Iztapalapa, Mexico.

HPLC analyses were made at the Central Analítica, Depto. de Biotecnología. CINVESTAV-IPN and directed by Elvira Rios, Cirino Rojas, and Gustavo Medina.

We would like to thank Alberto Bremauntz-Enriquez for reviewing the translation of the manuscript.

\section{REFERENCES}

[1] M. P. Bremauntz, L. G. Torres, L. O. Cañizares, E. Duran, L. Fernándz, "Trehalose and Sucrose Osmolytes Accumulated by Algae as Potential Raw Material for Bioethanol,” Natural Resources, Vol. 2, No. 3, 2011, pp. 173179. 
[2] R. Joset and M. Jeanjean, "Dynamics of the Response of Cyanobacteria to Salt-Stress: Deciphering the Molecular Events,” Physiologia Plantarum, Vol. 96, No. 4, 1996, pp. 738-744.

http://dx.doi.org/10.1111/j.1399-3054.1996.tb00251.x

[3] K. Satoh and K. Murata, "Stress Responses of Photosynthetic Organisms” Elsevier Science, Amsterdam, 1998.

[4] J. Chow, "Energy Resources and Global Development," Science, Vol. 302, No. 5650, 2003, pp. 1528-1531. http://dx.doi.org/10.1126/science.1091939

[5] E. Blumwald, J. Mehlhorn and L. Packer, "Studies of Osmoregulation in Salt Adaptation of Cyanobacteria with ESR Spin-Probe Techniques," Proceedings of the National Academy of Sciences, Vol. 80, No. 9, 1983, pp. 2599-2602. http://dx.doi.org/10.1073/pnas.80.9.2599

[6] D. Los and N. Murata, "Membrane Fluidity and Its Role in the Perseption of Environmental Signals," Biochimica et Biophysica Acta, Vol. 1666, No. 1-2, 2004, pp. 142157. http://dx.doi.org/10.1016/j.bbamem.2004.08.002

[7] A. Ben-Amotz and M. Avron, "Accumulation of Metabolites by Halotolerant Algae and Its Industrial Potential," Annual Review of Microbiology, Vol. 37, 1983, pp. 95119.

http://dx.doi.org/10.1146/annurev.mi.37.100183.000523

[8] A. Oren, "Diversity of Organic Osmotic Compounds and Osmotic Adaptation in Cyanobacteria and Algae,” In: J. Seckbach, Ed., Algae and Cyanobacteria in Extreme Environments, Springer, Berlin, 2007, pp. 639-655. http://dx.doi.org/10.1007/978-1-4020-6112-7_35

[9] Goldember, "Ethanol for a Sustainable Energy Future," Science, Vol. 315, No. 5813, 2007, pp. 808-810. http://dx.doi.org/10.1126/science.1137013

[10] G. Antolin, F. Tinaut, Y. Brinceno, V. Castano, C. Perez and A. Ramirez, "Optimisation of Diesel Production by Sunflower Oil Transesterification,” Bioresource Technology, Vol. 83, No. 2, 2002, pp. 111-114. http://dx.doi.org/10.1016/S0960-8524(01)00200-0

[11] J. R. Miranda, P. C. Passarinho and L. Gouveia, "PreTreatment Optimization of Scenedesmus obliquus Microalga for Bioethanol Production,” Bioresource Technology, Vol. 104, 2012, pp. 342-348.

[12] R. Rippka, D. Josette, J. Waterbury, M. Herdman and R. Y. Stanier, "Generic Assignments, Strain Histories and Properties of Pure Cultures of Cyanobacteria,” Journal of General Microbiology, Vol. 111, No. 1, 1979, pp. 1-61. http://dx.doi.org/10.1099/00221287-111-1-1

[13] M. Dubois, K. A. Gilles, J. K. Hamilton, P. A. Rebers and F. Smith, "Colorimetric Method for the Determination of Sugars and Related Substances,” Analytical Biochemistry, Vol. 28, No. 3, 1956, pp. 350-356.

[14] G. Hodaifa, M. Martínez, R. Orpez and S. Sanchez, "Inhibitory Effects of Industrial Olive-Oil Waste Water on Biomass Production of Scedesmus obliquus,” Ecological Engineering, Vol. 42, 2012, pp. 30-34. http://dx.doi.org/10.1016/j.ecoleng.2012.01.020

[15] H. Shih-Hsin, C. Chun-Yen and C. Jo-Shu, "Effect of Light Intensity and Nitrogen Starvation on $\mathrm{CO}_{2}$ Fixation and Lipid/Carbohydrat Production of an Indigenous $\mathrm{Mi}$ croalga Scenedesmus obliquus CNW-N," Bioresource Technology, Vol. 113, 2012, pp. 244-252. http://dx.doi.org/10.1016/j.ecoleng.2012.01.020

[16] Y.-H. Wu, Y. Yu, X. Li, H.-Y. Hu and Z.-F. Su, "Biomass Production of a Scedesmus sp. under Phosphorous Starvation Cultivation Condition," Bioresource Technology, Vol. 112, 2012, pp. 193-198. http://dx.doi.org/10.1016/j.biortech.2012.02.037

[17] P. Siver and I. Trainor, "Morpholical Control and Physiology of Scenedesmus Strain 170,” Phycologia, Vol. 20, No. 1, 1981, pp. 1-11.

http://dx.doi.org/10.2216/i0031-8884-20-1-1.1

[18] I. Fedina and K. Benderliev, "Response of Scenedesmus incrasstulus to Salt Stress as Affected by Methyl Jamonate,” Biologia Plantarum, Vol. 43, No. 4, 2000, pp. 625627. http://dx.doi.org/10.1023/A:1002816502941

[19] G. Demetriou, C. Neonaki, E. Navakoudis and K. Kotzabasis, "Salt Stress Impact on the Molecular Structure and Function of the Photosynthetic Apparatus-The Protective Role of Polyamines," Biochimica et Biophysica Acta, Vol. 1767, No. 4, 2007, pp. 272-280.

http://dx.doi.org/10.1016/j.bbabio.2007.02.020

[20] S. Shanab and H. Galal, "The Interactive Effect of Salinity and Urea on Growth, Some Related Metobolites an Antioxidants Enzymes of Chlorella sp. and Scenedesmus sp.," New Egyptian Journal of Microbiology, Vol. 7, No. 2, 2007, pp. 64-75.

[21] A. B. El-Sayed, M. M El-Fouly and E. A. A. Abou ElNour, "Immobilized Microalga Scenedesmus sp. for Biological Desalination of Red Sea Water: I. Effect on Growth,” Nature and Science, Vol. 8, No. 9, 2010, pp. 69-76.

[22] S. Shu, L.-Y. Yuan, S.-R. Guo, J. Sun and C.-J. Liu, “Effects of Exogenous Spermidine on Photosynthesis, Xanthophyll Cycle and Endogenous Polyamines in Cucumber Seedlings Exposed to Salinity," African Journal of Biotechnology, Vol. 11, No. 22, 2012, pp. 6064-6074.

[23] A. Kirrolia, N. Bishnoi and N. Singh, "Salinity as a Factor Affecting the Physiiologucal and Biochemical Trait of Scenedesmus quadricauda," Journal of Algal Biomass Utilization, Vol. 2, No. 4, 2011, pp. 28-34.

[24] M. Page-Sharp; C. Behm and G. Smith, "Involvement of Compatible Solutes Trehalose and Sucrose in the Response to SALT Stress of Cyanobaterial Scytonema Species Isolated from Desert Solils,” Biochimica et Biophysica Acta, Vol. 1472, No. 3, 1999, pp. 519-528. http://dx.doi.org/10.1016/S0304-4165(99)00155-5

[25] G. Markou, I. Angelidaki and G. Dimitris, "Microbial Carbohydrates: An Overview of the Factors Influencing Carbohydrates Production, and of Main Bioconversion Technologies for Production of Biofuels," Applied Microbiology and Biotechnology, Vol. 96, No. 3, 2012, pp. 631-645. http://dx.doi.org/10.1007/s00253-012-4398-0

[26] H. Gou, D. Maurycy, L. Liu, G. Qiu, S. Geng and G. Wang, "Biochemical Features and Bioethanol Production of Microalgae from Coastal Waters of Pearl River Delta," Bioresource Technology, Vol. 127, 2013, pp. 422-428.

[27] P. J. Rojan, G. Anisha, K. Nampoothiri and A. Pandey, "Micro and Macroalgal Biomass: A Renewable Source for Bioethanol,” Bioresource Technology, Vol. 102, No. 1, 2011, pp. 186-193. 